\title{
A MEMÓRIA SOCIAL COMO REPOSITÓRIO DO PLURALISMO LINGUÍSTICO-CULTURAL NO CONTEXTO BRASILEIRO
}

\section{THE SOCIAL MEMORY AS A REPOSITORY OF LANGUAGE- CULTURAL PLURALISM IN THE BRAZILIAN CONTEXT}

\author{
Ivonete da Silva Santos* \\ Alexandre António Timbane*
}

\begin{abstract}
RESUMO: Este artigo discute questões relacionadas à identidade linguística, cultura, língua portuguesa no Brasil, variação e variantes linguísticas, sob a perspectiva do estudo sobre a língua como sistema que agrega diferentes variedades, culturas e identidades. O desenvolvimento deste artigo tem como foco os objetivos geral e específico, a saber: explicar a existência de culturas na língua e na língua portuguesa enquanto instrumento de comunicação; evidenciar por meio de discussão teórica a participação dos elementos linguísticos e culturais na formação do ser social em contexto do português brasileiro. É uma pesquisa bibliográfica que analisa e discute teorias com enfoque para os debates de Bagno (2014), Vannucch (2011), Bosi (1992), Hall (2011), Bagno (2014), Mateus (2001) entre outros. O português falado no Brasil é resultado do acúmulo cultural, memorial e linguístico depositado na memória social ao longo dos anos. A construção da identidade do sujeito social a partir dos planos linguístico e cultural se constrói no cotidiano do uso da língua. A presença de várias culturas no Brasil originou a variedade do português brasileiro que não é uma outra língua, mas sim uma variedade da língua portuguesa como sistema. Em cada espaço lusófono a cultura foi moldando suas características, resultando na variação linguística intra e intergrupal. O multiculturalismo faz parte da formação, desenvolvimento ou conformação de uma língua no meio onde atua. Os falantes de uma determinada comunidade linguística carregam aspectos da memória histórica e da identidade dos seus antepassados e esses traços são incorporados permanentemente na língua. A transmissão dos valores culturais, morais e éticos só são possíveis porque os responsáveis pela transmissão se valem do sistema linguístico de modo particularizado, expondo outros aspectos culturais remotos no tempo e no espaço.
\end{abstract}

PALAVRAS-CHAVE: Cultura; Língua e Sistema; Memória social; Português brasileiro.

ABSTRACT: This article proposes a study on language, as a system that adds different varieties, cultures and identities. The general objective is to study language and social memory, relating them to the Brazilian socio-historical context. Specifically, the research aims to explain the existence of cultures in the language as an instrument of communication; Evidence through the theoretical discussion the participation of linguistic and cultural elements in the formation of the social being. It is a bibliographical research that analyzes and discusses theories with focus for the debates of Bagno (2014), Vannucch (2011), Bosi (1992), Hall (2011), Bagno (2014), Mateus (2001) among others. From the research it was concluded that the Brazilian Portuguese is a result of the cultural, memorial and linguistic accumulation deposited over the years. The construction of the identity of the social subject from the linguistic and cultural planes is built in the daily use of the language. The presence of several cultures in Brazil originated the variety of Brazilian Portuguese that is not another, but rather a variety of Portuguese as a system. In each lusophone

\footnotetext{
* Mestranda no Programa de Mestrado em Estudos da Linguagem (PMEL) da Universidade Federal de Goiás(UFG), Regional Catalão, Graduada em Letras Português (UFG/RC), email: nete.silva.santos@hotmail.com

** Professor e Pesquisador Visitante Estrangeiro, no Programa de Mestrado em Estudos da Linguagem (PMEL), da Universidade Federal de Goiás (UFG), Regional Catalão. Email: alextimbana@gmail.com
} 
space the culture was shaping its characteristics, resulting in intra and intergroup linguistic variation. The multiculturalism that is part of the formation, development or conformation of a language in the environment where it operates. The speakers of a particular linguistic community carry aspects of the historical memory and identity of their ancestors and these traits are permanently incorporated into the language. The transmission of cultural, moral and ethical values is only possible because those responsible for transmission use the linguistic system in a particular way, exposing other cultural aspects remote in time and space.

KEYWORDS: Culture; Language and System; Social memory; Brazilian Portuguese.

\title{
CONSIDERAÇÕES INICIAIS
}

O estudo sobre a língua só consegue ser efetivo quando a sua pesquisa parte de uma observação em contexto social, bem como da relação que a mesma mantém com o meio onde atua, com seus usuários e culturas próprias do local em que se insere. Tal como Labov (2008) demonstrou em seus estudos em Martha's Vineyard e em Nova York, estes estudos comprovaram definitivamente que seria inútil estudar a língua fora do seu contexto social. $\mathrm{O}$ estudo da Língua Portuguesa (LP) só faz sentido quando for realizado em contexto social, porque as manifestações da língua só se materializam na comunidade e em especial no indivíduo que é o portador da fala. A fala é entendida como "o conjunto de atividades físicas e mentais implicadas no ato pelo qual uma pessoa comunica a outra um determinado conceito (pensamento, noção ou emoção)" (COSERIU, 1979, p.20). A manifestação de fala ocorre de forma variada, caso contrário não teríamos interpretações semânticas, não teríamos variedades, variantes, dialetos e sotaques.

$\mathrm{Na}$ formação e na consolidação de uma variedade entra em ação um fenômeno importante: a memória social, coletiva e própria de um grupo social. Essa memória fica registrada na oralidade e nas últimas décadas por escrito. No entanto, existem várias memórias que a sociedade acumula ao longo dos tempos, desde a sua existência. O comportamento sociocultural que a sociedade brasileira apresenta hoje é resultado da memória social acumulada ao longo dos séculos da sua existência. Deste modo, no português brasileiro (PB), por exemplo, observa-se que este tem características próprias que diferenciam do português angolano, moçambicano, etc. $\mathrm{O}$ que diferencia uma variedade da outra é simplesmente a cultura e o percurso histórico percorrido que cada país. A língua, segundo Martinet ${ }^{1}$

\begin{abstract}
é um instrumento de comunicação que analisa a experiência humana de forma diferente em cada comunidade, constitui-se de monemas que são unidades dotadas de um conteúdo semântico e uma expressão fônica; esta expressão fónica se articula por sua vez em unidades distintivas e sucessivas, e fonemas, estes em número determinado em cada idioma, cuja natureza e as relações mútuas diferem também de uma língua para outra (MARTINET, 1967, p.20, tradução nossa).
\end{abstract}

Martinet levanta aqui a questão "experiência humana" que é para as análises um fator importante, pois cada povo tem suas experiências, possui suas realidades socioculturais que sempre devem ser tidas em conta quando se analisa uma língua.

Falando sobre a "Análise sociodiscursiva da saudação no grupo étnico-linguístico tsonga em Moçambique”, Timbane (2014a) mostra que na cultura dos tsonga do sul de Moçambique, a saudação não se realiza apenas com "oi" ou "bom dia". Isso não basta. Na saudação os

\footnotetext{
1 "Est un instrument de communication selon lequel l'expérience humaine s'analyse, différemment dans chaque communauté, en unités douées d'un contenu sémantique etd'une expressiona phonique, les monèmes; cette expressiona phonique s'artcule à son tour en unités distinctives et sucessives, les phonèmes, en nombre déterminé dans chaque langue, dont la nature et les rapports mutuels diffèrent eux aussi d'une langue à une autre".
} 
interlocutores não devem usar a $1^{a}$ pessoa do singular, mas sim do plural, narrando como estão os membros da família incluindo os acontecimentos mais importantes da vida das pessoas envolvidas na narração. Sendo assim, "O cumprimento fica mais longo ainda quando acontece no fim do dia, porque os falantes irão contar as atividades realizadas ao longo do dia. Este ritual da saudação pode ocorrer duas vezes com as mesmas pessoas desde que estes se veem" (TIMBANE, 2014a, p.101). Para além disso, as pessoas que estão se cumprimentando precisam verificar se há um acompanhante que está escutando, porque se existir deverá se passar a palavra para que essa pessoa feche a saudação, dizendo em língua xichangana hi hi yòleyò ndzava! ("eis aí as notícias!”). Se ele não tem nada a acrescentar responderá Pfalelani, quer dizer, "encerrem a saudação.” (TIMBANE, 2014a).

Este exemplo mostra claramente o que a língua transmite. A língua não comunica apenas, mas também revela a cultura de um povo, seus hábitos e costumes. Está na memória social e cultural dos povos tsonga, o uso da pessoa verbal e os tempos verbais. Isso fica impregnando na língua e essa regra básica os diferencia de outras etnias e povos.

A variação está inserida nessas diferenças e é influenciada pelo contato linguístico, tal como veremos no caso apresentado por Dietrich (2014). Falando sobre a "Conservação e inovação no campo léxico do parentesco: o caso do Mbyá e do Guaraní paraguaio (TupíGuaran1)" Dietrich revela como a interferência da modernidade vai construindo novos olhares e novas perspectivas sobre a língua, provocando variação e mudança. A pesquisa de Dietrich mostra que houve "abandono das estruturas sociais indígenas e o peso constante da outra língua, o espanhol, levaram e estão levando ainda ao abandono das estruturas semânticas do Guaraní tradicional, isto é, das estruturas relacionais, e também à perda de muitos dos termos específicos do Guaraní” (DIETRICH, 2014, p.210). O autor acrescenta que a

\begin{abstract}
terminologia atual do parentesco reflete a sociedade moderna, com menos estruturas hierárquicas familiares do que antes, com mais autonomia do indivíduo. As velhas estruturas hierárquicas conservaram-se apenas no núcleo familiar, na distinção relacional entre os filhos do varão e as crianças da mulher (DIETRICH, 2014, p.210).
\end{abstract}

Este aspecto está inserido no que Hall designa por "culturas emergentes" que possuem um sentimento de ameaça face às "forças da globalização, da diversidade e da hibridização" (HALL, 2003, p.46). Segundo Hall, a cultura é uma produção que se é da responsabilidade da comunidade e tem sua matéria-prima, seus recursos, seu trabalho produtivo que ocorre de forma imperceptível ao longo de décadas e séculos.

A língua é parte da cultura de um povo, fundamentalmente, é ela um sistema importante para que sejam estabelecidas relações comunicacionais entre os falantes de uma determinada comunidade, a depender da necessidade e da urgência que tem os indivíduos no momento da comunicação. Para melhor entendermos essa questão é fundamental que lancemos um olhar mais profundo sobre as questões sociais que envolvem o diálogo entre língua(gem), meio e falante.

Diante desses pressupostos, este artigo delineia questões sociolinguísticas do PB tendo em conta os elementos culturais e históricos que fazem parte da memória social brasileira, já que num primeiro momento toda língua sofre influências multiculturais ao se expandir mundo a fora.

$\mathrm{Na}$ primeira seção, o artigo aborda questões relacionadas a identidade do ator social. Essas questões constituem-se em dois planos: o linguístico e o cultural, de modo que a importância da relação cultural e linguística para a formação da identidade social dos membros de uma determinada comunidade seja observada como fator indissociável da relação sujeito e meio

\footnotetext{
2 É a segunda língua materna mais falada de Moçambique, pertencente ao grupo tswa-ronga (S50), localizada geograficamente nas províncias de Maputo, Gaza e Inhambane por cerca de 11,4\%, segundo dados do Instituto Nacional de Estatística de Moçambique (2009).
} 
onde se insere. $\mathrm{Na}$ segunda seção, discute-se aspectos relacionados à cultura demonstrando-se como se formou a LP e as influências culturais que contribuíram para tal. Na terceira seção, o debate se dá em torno do conceito de memória social como repositório do pluralismo linguísticocultural da LP, dando especial atenção ao caso do Brasil. Esta seção é interessante porque desenvolve um debate capaz de mostrar a relação entre LP e culturas brasileiras, já que a LP ao adentrar ao Brasil emergiu num caudal cultura interno e externo, se tivermos em atenção às culturas vindas de fora e as já existentes no território brasileiro (por ex.: culturas africanas e indígenas). Outra questão que pertinentemente se discuti neste artigo é a variação linguística intra e intergrupal, de modo a exemplificar que a língua como sistema de signos muda e se adapta ao ambiente de atuação, existindo na/para a comunidade que a usa.

É importante deixar claro que esta pesquisa é de caráter bibliográfico, pois resulta da leitura, análise e discussão de diversas literaturas disponíveis sobre o tema. A pesquisa permitiu compreender vários conceitos e definições que criavam penumbras na compreensão e nas colocações acerca dos temas em apreço, tal como veremos a seguir.

\section{A identidade do ator social se constitui em dois planos: o linguístico e o cultural.}

A identidade é o conjunto de significações que são atribuídas pelo sujeito através da sua experiência diante das situações que se inscrevem em sua vida, já que se faz necessário no processo identitário a coesão entre meio/sujeito, passado/presente e entre o "eu" e o "outro". Sendo assim, a identidade não é fixa, está em constante variação e mudança a depender das situações experienciadas por cada ator social. Até porque o ator quando inserido no cenário social se sujeita as coordenadas que o meio exige, atualizando-se e atuando de acordo com as experiências vivenciadas.

Por essa razão, a identidade deve ser afirmada ou reafirmada dependendo das coordenadas do meio ou das situações experimentadas pelo ator social. O que significa dizer que, o sujeito possui várias identidades sociais, a depender das circunstâncias e dos momentos vivenciados. Do momento, pode-se afirmar que a identidade é na verdade um processo que atinge o sujeito social estendendo-se para dentro da comunidade. A identidade social se define também como sentimento de pertença a um determinado grupo ou comunidade, já que a sua construção está intimamente relacionada à fatores contextuais, linguísticos, culturais e históricos. Sob o ponto de vista linguístico é mais notável quando se fala de "variação estilística" discutida de forma profunda nos estudos de Gorski, Coelho e Souza (2014). Sobre esta questão aprofundaremos mais adiante.

Portanto, as "nossas sociedades são compostas não de um, mas de muitos povos. Suas origens não são únicas, mas diversas" (HALL, 2003, p. 30) e é justamente está diversidade que determina o modo como cada ser social se apresenta ou venha a se apresentar ao mundo, demonstrando a sua identidade de acordo com as exigências do ambiente em questão. A efetivação da identidade se dá a partir do contato entre o "eu" e o "outro". Este contato se constitui por movimentos culturais e linguísticos interiorizados no interior social de cada grupo que compõe o contato, já que os grupos fazem parte de uma história cultural e linguística comum a toda comunidade de pertença. Por isso, o ator social como membro de um grupo é visto como representante de uma comunidade histórico-cultural linguisticamente constituída.

A cultura constitui "o modo de viver típico, o estilo de vida comum, o ser, o fazer e o agir de determinado grupo humano, desta ou daquela etnia" (VANNUCCH, 2011, p. 26), ou seja, a cultura se traduz como atitudes e comportamentos cristalizados no interior de uma determinada comunidade. O conjunto cultural de uma comunidade é muito mais intenso do que aparentemente se apresenta na individualidade. Sendo assim, a cultura de um povo é fundamental para situar o sujeito dentro do grupo ao qual faz parte, essa cultura serve para incluí-lo ou excluílo de um grupo. O que acontece com a cultura se manifesta também na língua, pois tal como 
aponta Lopes (1980, p.21) "cada língua natural é um microcosmo do macrocosmo que é o total da cultura dessa sociedade". O fator de exclusão ocorre quando os sujeitos de determinada comunidade resolvem contatar com outra comunidade diferente da sua, ou não comungam os ideais comuns aos membros do grupo contatado, ou quando preferem fazer parte daquele grupo ao invés desse. A comunhão cultural é inclusiva quando agrega membros ao grupo, quer dizer, quando integra a participação de um ou mais membros no grupo. Mas, de modo geral, a cultura está sempre agregando ou excluindo sujeitos se tivemos em conta que todos os atores sociais fazem parte de uma ou mais culturas.

Sendo assim, o modo como se apresenta o sujeito ao mundo denuncia as raízes culturais que estruturam a sua perpetuação dentro da comunidade de pertença. Ou seja, o sujeito é notado pelo outro através das características próprias da cultura que o identifica como diferente em relação ao outro. O contato entre o "eu" e o "outro" tende sempre a desenvolver uma relação de conhecimento de si e do outro, vez que o diferente sempre se sobressai numa situação de contato e isso revela ao mundo qual o posicionamento do sujeito no meio social e os valores que atribui a tudo que o cerca. No plano linguístico a interação do sujeito com o "outro" depende muito dos significados apreendidos dentro da comunidade linguística que faz parte. Deste modo, se faz necessário retomar a definição de Saussure (2006) quando afirma que a língua é um conjunto de signos abstratos, aprendidos coletivamente como herança histórica. Ou seja, é um conjunto de signos com possibilidades combinatórias que permitem ao usuário a escolha de combinações signicas que atendam as necessidades comunicativas que lhes interessa resolver.

A língua é fator determinante para a realização do processo de construção identitária, uma vez que "abrir a boca e começar a falar uma língua é instantaneamente, criar um ambiente sociocultural e sociocognitivo moldado pelos falantes daquela língua. É criar em contexto de relações e interações. Ou seja, língua é contexto" (BAGNO, 2014, p.17). Seguindo o raciocínio de Bagno é perceptível a naturalidade da relação entre língua, meio e passado histórico, já que a língua como contexto está adequadamente relacionada com a história do local onde atua.

Uma língua é capaz de traduzir em palavras as emoções, sentimentos e pensamentos que povoam o interior do ator social. As palavras são provas concretas do modo como o indivíduo vê, pensa e interpreta o mundo. Por exemplo, os brasileiros têm hábito de memorizar nomes de pessoas que lhes são apresentadas. Para um moçambicano da etnia tsonga, o nome das pessoas é tão íntimo (privado) que não se deve memorizar, mas sim o nome da família. Portanto, usar uma ou mais línguas tendo relevância maior à apreendida desde os primeiros anos de idade, se configura como retrato do mundo para o sujeito em questão e está carregada de cultura, vez que os planos linguístico e cultural se unem de modo amalgamo e dão sustento à construção da identidade do sujeito. Na língua xichangana não existe palavra para designar "neve", nem a expressão "Feliz natal" porque são realidades socioculturais de outros povos. Sendo assim, é visível a importância da língua e da cultura dentro de uma comunidade, sendo aquela reveladora da cultura comum aos membros da comunidade em questão.

Terminamos esta seção retomando colocações de Camara Jr. quando argumenta que a comunicação social só se processa no intercambio cultural tomando duas maneiras, a saber: "a) dando-lhe um aditamento linguístico, como a oração na religião, as leis, as regulamentações na indústria, etc.; b) propiciando a atuação uns com os outros dos membros participantes de uma atividade cultural, com as ordens, explicações etc." (CAMARA JR., 1989, p.21). Ou seja, o intercâmbio cultural é um processo social que resulta na troca de experiências fundamentais no passado social e histórico das respectivas comunidades.

\section{A(s) cultura(s) da e na língua portuguesa}

Definir cultura é estabelecer, ao mesmo tempo, relações com a língua. A língua nos parece uma peça-chave na interação entre os humanos, entre culturas iguais e diferentes. A 
existência de costumes cristalizados no interior de determinada comunidade é fator fundamental na determinação do modo como esta comunidade vê o mundo ao seu redor. Significa dizer que as crendices, atitudes e hábitos corriqueiros praticados coletivamente revelam a real cultura que vigora no interior da comunidade em apreço. Diante disso, o significado de cultura é complexo e abrange uma série de práticas que particulariza esta comunidade em relação àquela. A cultura é

\begin{abstract}
o conjunto de práticas sociais, situadas historicamente, que se referem a uma sociedade e que a fazem diferente de outra. Baseia-se na construção social de sentidos as ações, crenças, hábitos, objetos que passam a simbolizar aspectos da vivência humana em coletividade. Construída socialmente no cotidiano das relações humanas demanda que seja definida no seio das relações sociais e históricas que a amparam e por ela são caracterizadas (PAULA, 2007, p. 74).
\end{abstract}

Desta forma, falar a LP é literalmente fazer parte de uma história cultural complexa que se disseminou durante o processo da sua expansão mundo a fora. A cultura latina, romana, árabe etc. fazem parte dessa história, ainda que cada uma tenha se inscrito nela de modo diferenciado. A cultura é uma herança social que se constitui através das contribuições individuais provenientes de experiências pessoais e representativas de atitudes comuns ao grupo de pertença. Partindo desse raciocínio, percebe-se que as manifestações culturais são para evidenciar as diversidades culturais que compõem o mundo e por isso é necessário a valorização das raízes que originariamente o representa, tendo em conta a composição heterogênea das sociedades como prova de não unicidade e sim de origens várias dos povos que as compõem. Só para ilustrar, Lopes (1980) exemplifica explicando que,

\footnotetext{
o indivíduo que guia um automóvel é chamado, em francês, de chauffeur, em espanhol de conductor, em inglês de driver, em português de motorista; isto significa que os franceses associam tal indivíduo com a sua atividade de aquecer o motor para pôr a máquina em movimento; os espanhóis e ingleses o associam com o ato de dirigir o carro, enquanto nós, falantes do português, o associamos diretamente com o motor do veículo. Trata-se de uma mesma atividade, mas a análise que cada língua pratica nessa realidade resulta na apreensão de um aspecto particular de uma série de operações, e esse aspecto focalizado difere de uma para outra comunidade de falantes (LOPES, 1980, p.22, grifos do autor).
}

Este exemplo ilustra a arbitrariedade do signo, tal como Saussure colocou entendendo a língua como "um produto social da faculdade de linguagem e um conjunto de convenções necessárias, adotadas pelo corpo social para permitir o exercício dessa faculdade nos indivíduos" (SAUSSURE, 2006, p.17). Ora, se a língua é um produto social, como é que essa mesma sociedade pode existir sem cultura? Está claro nesta afirmação que Saussure tenta mostrar que a língua é comandada pelas convenções socioculturais adotadas pela comunidade sendo que o léxico é face mais marcante, visível, mais notável na língua (TIMBANE, 2014b) e a cultura molda o modo como essa língua deve ser expressa em diferentes situações comunicativas.

A lexicultura, como sendo o conjunto do léxico característico de uma determinada cultura se divide em geral e específica. Entende-se por lexicultura geral, o conjunto de itens lexicais que são identificados por toda comunidade linguística, neste caso, comunidade lusófona" (TIMBANE, 2014b, p.47). Existem traços, itens lexicais comuns que ocorrem na lusofonia e que permitem a intercompreensão entre os falantes da língua portuguesa. Timbane (2014b) os entende como gerais, uma vez que o consenso entre os membros da comunidade linguística tornam comum o uso de termos iguais nas comunidades lusófonas. Por outro lado, entende-se por lexicultura específica, "o conjunto de itens lexicais que caracterizam uma variedade ou variante específica" (TIMBANE, 2014b, p.47). Aqui engloba-se itens lexicais específicos de variedades, de variantes e de dialetos característicos de uma comunidade mais restrita. 
A transmissão dos valores culturais, morais e éticos importantíssimos para o desencadeamento e integração do ator social dentro da comunidade sociolinguística, só são possíveis porque os responsáveis pela transmissão se valem do sistema linguístico de modo particularizado, expondo-os aos outros aspectos culturais remotos no tempo e no espaço. Tudo depende naturalmente da significação da cultura em atos linguísticos que tem por finalidade a transmissão de hábitos corriqueiros e importantíssimos para o desenvolver da identidade cultural do indivíduo e do grupo a qual pertença, é nesse sentido que as abstrações e impressões que tem o grupo sobre o universo, em especial o seu universo, são marcadas pela heterogeneidade e diversidade proposta por cada espaço de produção da cultura. Portanto,

\begin{abstract}
possuir uma identidade cultural nesse sentido é estar primordialmente em contato com um núcleo imutável e atemporal, ligando ao passado o futuro e o presente numa linha ininterrupta. Esse cordão umbilical é o que chamamos de tradição, cujo teste é o de sua fidelidade às origens, sua presença consciente diante de si mesma, sua 'autenticidade' (HALL, 2003, p. 29, grifo do autor),
\end{abstract}

O que significa dizer que um grupo ao praticar atos frequentes e comuns que o identifica e os diferencia dos demais no mundo é na verdade a prática de uma tradição veiculada por uma transmissão além séculos que se arrasta na realidade atual como resposta à manutenção do sentimento de pertença a uma cultura própria e específica. Com isso, ocorre a atualização dia a dia dos traços culturais como elo entre o presente e o passado numa perspectiva de um futuro articulado com as raízes originais.

Se a língua é elemento fundamental para que o ator social se conheça e reconheça o outro, de modo a se situar socialmente no mundo é natural que a língua seja o veículo de transmissão do passado sociocultural e histórico de um determinado povo ou comunidade. No entanto, à língua não se pode atribuir somente essa função veicular porque é ela, especialmente, a própria cultura de um povo. Percebe-se que a língua é uma tradução profunda do processo subjetivo que modifica a realidade frente ao indivíduo.

Para muitos, a LP provém do latim (CASTILHO, 2010; BECHARA, 2009) para outros, o português provém do galego (BAGNO, 2014; TEYSSIER, 2014). Em ambos os existe uma constatação comum segundo a qual o nosso português surgiu na Península Ibérica e se espalhou pelo mundo devido à colonização. O português junto com o francês, o italiano, o castelhano, o catalão são línguas românicas. Devido à romanização que se deu na Península Ibérica foi possível graças ao contato entre vários povos que misturaram suas culturas e suas línguas ao se instalarem na região que serviu de berço para o nascimento do português. Esse contato entre os povos recém-chegados e os naturais da Península permitiu que as línguas autóctones influenciassem na evolução do latim, forçando a formação do português como "sistema" (COSERIU, 1979).

A pessoa humana é um ser complexo e é sempre definido pela linguagem e pela razão que manifesta, o que significa dizer que, não haveria racionalidade se não existisse a linguagem (AUROUX, 2009). Por causa dessa racionalidade e dinamicidade, a língua não é estática, fechada e pura. É um sistema linguístico constituído por elementos culturais e linguísticos de grupos variados. Nesse caso, o passado histórico que sustenta hoje a LP em Portugal em relação às diferentes faces que a mesma adquiriu fora de Portugal está intimamente ligado aos fatos políticos, sociais, culturais e históricos que impostamente foram sendo agregados no espaço lusófono. As mudanças na sociedade são constantes e estão sempre acompanhando os avanços propostos pelos novos tempos, pelas novas tecnologias e pela globalização fato que condiciona a necessidade de mudança linguística. Por isso mesmo, "nenhuma língua humana viva, em, nenhum histórico, é um bloco compacto, homogêneo, pronto e acabado. A língua (como tudo mais no universo) não para, está sempre se transformando" (BAGNO, 2014, p. 80). As considerações de Bagno expressas na citação acima justificam a expansão da LP para além-mar e 
a sua adaptação aos espaços onde foi-se instalando ao longo do tempo, vez que o português se encontra direta ou indiretamente em todo mundo.

Partindo da discussão que se deu até agora importa incluir nela os elementos culturais que compõem a existência da LP em cada espaço que a sustenta. Até porque o que diferencia a atuação da LP em Portugal para com os demais países lusófonos é justamente o tipo de formação cultural que engendrou a sua recepção. No caso de Portugal as culturas participantes foram: autóctones, árabes, romanas entre outras que com certeza por ali passaram (BECHARA, 2009). Já no caso do Brasil, a formação do PB resulta da interação entre as culturas indígenas, africanas, portuguesas, italianas etc. (DIETRICH, 2014; TIMBANE e REZENDE, 2016).

É fundamental a valoração das culturas para se entender o modo de atuação de qualquer língua, até porque ela como sistema amplo e não restrito a um determinado grupo está sujeita às coordenadas do meio ao qual fazem parte seus usuários. Isso quer dizer que a língua está intimamente relacionada com o meio onde atua e é indissociável do contexto em que ocorre a comunicação e toda essa relação está relacionada com as "condições sociais e históricas" que justificam a sua atuação (SOARES, 1998). A existência de uma mesma língua em diferentes espaços geográficos não pressupõe um círculo cultural idêntico, por isso é tão importante o estudo da língua junto à cultura do local onde a língua está inserida (SAPIR, 1954; PAULA, 2007). Diante disso é pertinente dizer que a LP é um sistema maior que coexiste em espaços diferentes pertencendo a culturas diferentes. Portanto, a LP ao se desenvolver se constituiu por meio de contributos de várias culturas linguísticas e sociais diferentes.

\section{Memória social como repositório do pluralismo linguístico-cultural}

O português é uma das línguas mais faladas no mundo, mas é no Brasil onde se encontra o maior número de falantes que a tem como língua materna. Nas últimas décadas, os países africanos de expressão portuguesa têm registrado um número crescente de falantes de português como segunda língua embora haja interferência constante das línguas africanas. A variação e a mudança percorrerem fases da vida e da história de qualquer povo. Tanto a variação quanto a mudança se desenvolvem de forma silenciosa e imperceptíveis na comunidade linguística. Nem toda a variação resulta em mudança, mas toda mudança é resultado de uma variação (TIMBANE, 2014b). Discutir estes aspectos no contexto do Brasil é interessante porque nenhuma língua viva escapa ao processo 'normal' que ocorre em todas as línguas: verbais e de sinais. É na memória linguística e social onde se encontram traços que nos permitem afirmar que estamos falando/escrevendo em LP. Muitos aspectos, sobretudo lexicais e fonéticos se distanciaram da variedade europeia do português fato que nos leva a concluir que a língua é cultura e carrega a memória social de um povo.

Utilizar as palavras jaburu, tuiuiú, tuiuguaçu, tuiú-quarteleiro, tuiupara, rei-dos tuinins, tuim-de-papo-vermelho, cauauá, jabiru identifica a pertença cultural do falante. Neste caso, tratase de nomes de uma única ave típica da América do Sul cujas características são: "patas altas, pescoço nu e preto, na parte inferior um papo nu e vermelho, com plumagem branca com 1,4m" (TIMBANE; REZENDE, 2016, p.390). Os angolanos, os moçambicanos não conhecem estes nomes, pois a ave não é comum naqueles lugares. Mas na memória coletiva (HALBWACHS, 2006) dos brasileiros a ave existe e é o povo brasileiro que foi atribuindo nomes à mesma ave em cada região. Outra questão importante é a de que a maior parte desses nomes provêm das línguas da família tupi-guarani faladas pela população indígena. A memória social não deve ser vista e nem interpretada como a única e exclusiva determinante do comportamento social, mas sim deve ser vista como parte de variadas culturas e comunidades diferentes. Da mesma forma que não existe uma cultura homogênea não existe uma língua homogênea. Todas as línguas são resultado de outras línguas. Para Camara Jr. (1989, p.21), 
funcionando na sociedade para a comunicação dos seus membros, a língua depende de toda a cultura, pois tem, de expressá-la a cada momento. É resultado de uma cultura global. Tal não acontece com os outros aspectos culturais: em cada um deles se refletem outros, é verdade, como as concepções religiosas na arte, a arte na indústria, e assim por diante; mas nenhum deles existe para expressar todos os outros.

Por isso é importante estudar a língua sob duas perspectivas: a macro e a micro. Sob a perspectiva macro pode-se pensar nas várias culturas que alimentam as adequações sofridas pela LP e pela sua sobrevivência em cada comunidade de falantes que a usam. Isso quer dizer que as culturas africanas, as asiáticas, as americanas e as europeias entre outras que acolheram a LP são possuidoras de um sistema maior. No caso da cultura brasileira não ocorreu fato diferente dos demais, já que o sistema maior ao conhecê-la não resistiu e acabou se adaptando às necessidades da comunidade brasileira. Para cada pessoa, identificar-se como parte de uma cultura consiste num processo de realização cultural específica ligada abstratamente aos hábitos, costumes etc., do espaço sócia, em que se insere o indivíduo (MATEUS, 2001). No entanto, é pertinente a acepção de que a LP seja de várias culturas, tendo em conta o seu caráter multicultural. Sendo assim, é perceptível a dimensão macro, no sentido de amplitude, da participação da LP como parte das culturas africanas, brasileiras, portuguesas, asiáticas etc.

Em relação a convivência da LP com as culturas locais o estudo se volta para a perspectiva micro, já que a macro tem a ver com culturas maiores. Pensando assim, seja a LP parte de variadas culturas, pois o português que se desenvolveu em cada espaço lusófono mantém uma relação íntima com as culturas próprias do espaço de atuação. É esta característica que a condiciona a ser parte também de culturas menores, pertencente ao grupo da micro cultura. No contexto do Brasil, o português adquiriu características próprias e diferenciadoras que permitem celebrar a história do povo brasileiro. Daí a importância dos estudos da língua sob a perspectiva micro, já que não é possível a separação entre língua e cultura, pois as culturas menores que circulam o interior de uma determinada comunidade são fatores importantes no processo de diferenciação da comunidade linguística em relação as demais comunidades no mundo. As várias culturas dentro do contexto brasileiro funcionam como modificadoras da LP que chegou ao Brasil no séc. XV.

As culturas micros brasileiras: gaúcha, goiana, mineira, paulista, baiana etc. compõem um conjunto cultural restrito e diversificado que fundamenta a existência de variante dentro do Brasil, realidade que revela costumes e valores interligados e ao mesmo tempo diferentes. Bosi (1992, p. 308) confirma que "estamos acostumados a falar em cultura brasileira, assim, no singular, como se existisse uma unidade prévia que aglutinasse todas as manifestações materiais e espirituais do povo brasileiro". Em outras palavras não existe no Brasil e em qualquer outro país uma unicidade cultural, existe sim uma pluralidade de culturas que se relacionam através da língua em uso. Nesse sentido, "O que se dá com a raça, dá-se com a cultura (...) línguas sem qualquer parentesco partilham de uma só cultura; línguas intimamente cognatas - quando não uma língua única - pertencem a círculos de cultura distintos" (SAPIR, 1954, p. 210-211). A LP como única língua sobrevive dentro de espaços diferentes e culturas diferentes. A acepção de Sapir ao dizer que uma única língua pode comungar "cultura distintas" ou várias línguas comungam uma mesma cultura é plausível porque se as línguas adquirem faces novas a depender do ambiente onde vive seus usuários é natural que a língua em uso se interaja com o meio em si. Deste modo, a comunhão que a LP faz em nível macro e micro em relação as culturas é fundamental para caracterizá-la como parte destas ou daquelas cultura.

As culturas macros são aquelas que sustentaram a formação ou desenvolvimento da língua atual falada no Brasil e a micro tem a ver com as culturas que desenvolveram juntas com a formação dessa língua atual. De modo mais claro, o PB se desenvolveu sob culturas africanas, portuguesas, indígenas etc., num primeiro momento. Num segundo momento, as características 
que a diferencia das demais variedades da LP são marcadas pelas características culturais internas, por isso o PB é também da cultura baiana, da gaúcha, da mineira etc.

Contudo, ao estudar a história da LP no Brasil percebe-se a tamanha transformação ocorrida ao logo do tempo pela árdua atualização da LP dentro do espaço brasileiro. Essa situação resultou em configurações que a distanciou da falada pelos portugueses, o que naturalmente ocorre com qualquer sistema transplantado, até porque a língua em si não é fixa e nem estática estando sujeita às influências das diversidades culturais, sociais e adaptações linguísticas oferecidas pelo meio em que a língua se instala. Os estudos de Castilho (2010), Perini (2010), Bagno (2012) revelam com propriedade as características do PB. Com isso, importa dizer que ocorre uma batalha entre as diferentes percepções linguísticas vigentes no interior de cada grupo que ao contatarem se estranham, mas essa situação conflitante que se instala, ora gerando bons resultados e, como a adaptação do sistema à realidade necessária de cada comunidade linguística, ora negativamente soterrando os demais sistemas existentes no mesmo espaço. Dessa forma, se consolida as várias faces adquiridas pela LP em cada espaço geográfico transplantado. Portanto, a LP é a língua das culturas, pertence as culturas que de algum modo sustentou as suas transformações no passado e é no presente parte das culturas que compõem o todo brasileiro.

No entanto, "uma língua, em face do resto da cultura, é 1) o seu resultado, ou súmula, 2) o meio para ela operar, 3) a condição para ela substituir. E mais ainda: só existe para tanto. A sua função é englobar a cultura, comunicá-la e transmiti-la através das gerações" (CAMARA JR., 1989, p.22). Em outras palavras a língua é sempre o veículo condutor responsável pela transmissão e comunicação da cultura no tempo e no espaço.

\section{A variação linguística intergrupal e intragrupal}

Ao longo dos debates desta seção traremos o nosso entendimento com relação aos conceitos de variedade, variante, dialeto e sotaque. Até aqui, ficou claro que as línguas, enquanto formas de comportamento social (LABOV, 2008) jamais ficam estáticas, variando segundo condicionadores linguísticos e extralinguísticos. Para Labov (2008, p.336) "uma mudança pode começar primeiro num grupo social localizado em qualquer ponto da hierarquia social." A variação linguística é um fenômeno que diz respeito às diferentes possibilidades de usos de uma mesma língua em espaços geográficos distintos. Segundo Coelho et al. (2015) a variação pode ocorrer dentro da língua (lexical, fonológica, morfológica, sintática e discursiva) ou fora da língua (regional, social, estilística, variação na fala e na escrita). As variações fonéticas e lexicais são as mais salientes e retratam a ocorrência da variação, vez que existem vários termos para se referir a uma mesma coisa/fenômeno dentro de uma mesma língua. Este fenômeno é constante no interior de uma dada comunidade linguística.

Se o falante é brasileiro provavelmente usará o termo ônibus para se referir ao veículo que transporta várias pessoas ao mesmo tempo, podendo ser coletivo ou executivo. Se o falante for um moçambicano, ao olhar para o mesmo veículo o chamará de machimbombo, pois a sua realidade sociocultural condiciona este uso ao invés daquele utilizado pelo falante brasileiro. Tudo isso, é fruto de uma confluência social e histórica que arraigada com a cultura dominante influenciaram fortemente as configurações que tomaria o conjunto lexical usado em cada país lusófono.

Sendo assim, importa dizer que a variação linguística é um fenômeno complexo e amplo, pois abrange não só a mudança linguística de uma língua em nível externo, mas também a mudança em nível interno, aquela que diz respeito às mudanças que ocorrem dentro de uma mesma comunidade. Ou seja, o brasileiro pertence à comunidade linguística do Brasil, e por sua vez faz parte de um dos grupos que constitui a comunidade linguística brasileira em si. O que significa dizer que ele utiliza uma das variantes faladas neste espaço geográfico. Esse falante brasileiro é do Sul, do Norte, Nordeste, Centro-Oeste ou Sudeste do Brasil. Enfim, ele faz parte 
de uma das regiões brasileiras. Partindo desse raciocínio, é fácil entender que um gaúcho não fala o português da mesma forma que um goiano, ou que um baiano não usa o português da mesma forma que um mineiro e assim sucessivamente. O que acabamos de descrever aqui, são variantes do $\mathrm{PB}$, pois elas especificam a origem do indivíduo dentro de um mesmo espaço políticogeográfico. Coelho et alli. (2015) dão exemplos do uso dos pronomes "tu" e "você" como marcas de variantes.

Nesse sentido, toda a mudança efetuada numa língua não é um processo desregrado ou sem qualquer critério. É regida por regras do próprio sistema. Sendo assim, "a mudança linguística, como tudo o que se refere ao processamento mental, decorre de uma elaboração conjunta, de uma atividade coletiva. Nenhuma pessoa pode mudar sozinha, o que quer seja na língua" (BAGNO, 2014, p. 70). O processo que dá origem ao fenômeno de variação linguística é fundamentalmente um processo coletivo, já que a sua concretização depende da atitude coletiva dos usuários. Portanto, a mudança linguística é histórica, social e cultural, a sua configuração depende dos aspectos mais relevantes de cada uma dessas dimensões para se efetivar como característica própria de determinada região ou país.

No Sul do Brasil é comum o uso da palavra rancho para se referir as compras alimentícias mensais, enquanto que em Goiás o mesmo termo é usado para designar uma cabana ou casa simples, feita de palha de coqueiro, de milho ou de arroz. Nesse caso, o termo "rancho" é utilizado para designar coisas diferentes dentro de uma mesma língua. Trata-se de uma variação semântica em que temos uma palavra utilizada com significados diferentes. Ainda em nível lexical, as palavras mandioca, macaxeira e aipim são variantes usadas em regiões diferentes do Brasil para designar um mesmo alimento. Outro exemplo, seria do citrus reticulata que é conhecida em diversos lugares do Brasil como tangerina, mexerica, laranka-mimosa, mandarina, fuxiqueira, poncã, manjerica, laranja-cravo, momosa, bergamota, clementina e por aí em diante. Nestes exemplos ilustram que estamos diante de variantes lexicais do PB. Castilho (2010, p.198) conclui afirmando que "o conjunto de variantes configura uma variação, e o conjunto de variações configura a variedade (...)". Ou seja, as diferenças linguísticas no interior de uma comunidade linguística condicionam a diferenciação entre as diferentes comunidades de uso de uma mesma língua.

Para Bagno (2011), o termo dialeto está ligado ao aspecto da colonização que considerava as línguas de povos dominados como dialetos. Por essa razão, "a separação entre língua e dialeto é eminentemente política, escapa dos critérios que os linguistas tentam estabelecer para delimitar tal separação" (BAGNO, 2011, p.382). O sotaque está ligado à forma como cada falante pronuncia as palavras ou as frases. Falar de sotaque é ao mesmo tempo analisar a fonologia individual de cada falante (o idioleto). Os sotaques podem variar segundo o sexo, etnia, grupo social, classe, região, idade, etc. O sotaque abarca as diferenças do ritmo, do timbre, da entoação, da ênfase e das diferenças fonêmicas dos falantes de uma determinada língua ou variedade.

Todos os exemplos que foram apresentados servem de modelo e confirmam a ideia de que toda língua está sujeita às mudanças, sejam elas em nível interno ou externo. É importante considerar que "a forma do comportamento linguístico muda rapidamente à medida que muda a posição social do falante. Essa maleabilidade da língua sustenta sua grande utilidade como indicador de mudança social" (LABOV, 2008, p.140). Contudo, a LP é um sistema maior que permite essas mudanças, a depender das configurações históricas, sociais e culturais do local onde atua. O PB é uma variedade da LP que é visivelmente diferenciada das demais variedades do português (TIMBANE e REZENDE, 2016). Então, a LP é o sistema que deu surgimento às ramificações das variedades faladas na lusofonia. Daí, a importância de conceituar essas as variedades sob a perspectiva intergrupal, já que cada espaço geográfico onde atua o português agregou, e em muitos casos ainda agrega, traços diferentes que os diferencia frente ao contato de diferentes comunidades de uso da LP. Nesse caso, a 
influência das línguas que estiveram em contato com o português na constituição da variedade brasileira tem como corolário a interpretação das referências culturais dos povos que as falavam na constituição do povo brasileiro. Igual caminho de interinfluências culturais percorreram os portugueses. Religião, música, artes plásticas e literárias, relações sociais e parentais, etnicidade, referenciais de gênero e de juventude desvendam formas especificas de estar no mundo que, tal como a língua, variam no tempo e no espaço, mas distinguem de modo evidente e global, as sociedades dos dois lados do Atlântico (MATEUS, 2001, p. 19).

O pensamento expresso na citação acima corrobora para a reflexão de que a variedade brasileira integra um conjunto agregado por um sistema maior. Dentro deste sistema coexistem variedades que se inter-relacionam quando partilham as bases linguísticas fixas permitidas pelo próprio sistema. Deste modo, a visão de variação intergrupal dentro do estudo do português brasileiro está relacionada a sua localização no todo linguístico que é a LP.

A figura 1 mostra de forma mais resumida, o que acontece no discurso. Existe na verdade um sistema representativo, aquele que está acima de tudo, comanda a língua e que dita as regras de funcionamento (COSERIU, 1979). Mas a manifestação prática desse sistema só se concretiza na fala através do idioleto, que se liga ao estilo individual. $O$ sistema afetivo e o representativo se unem para o que se chamada linguística no seu sentido lato.

Figura 1: A língua como representação individual e coletiva.

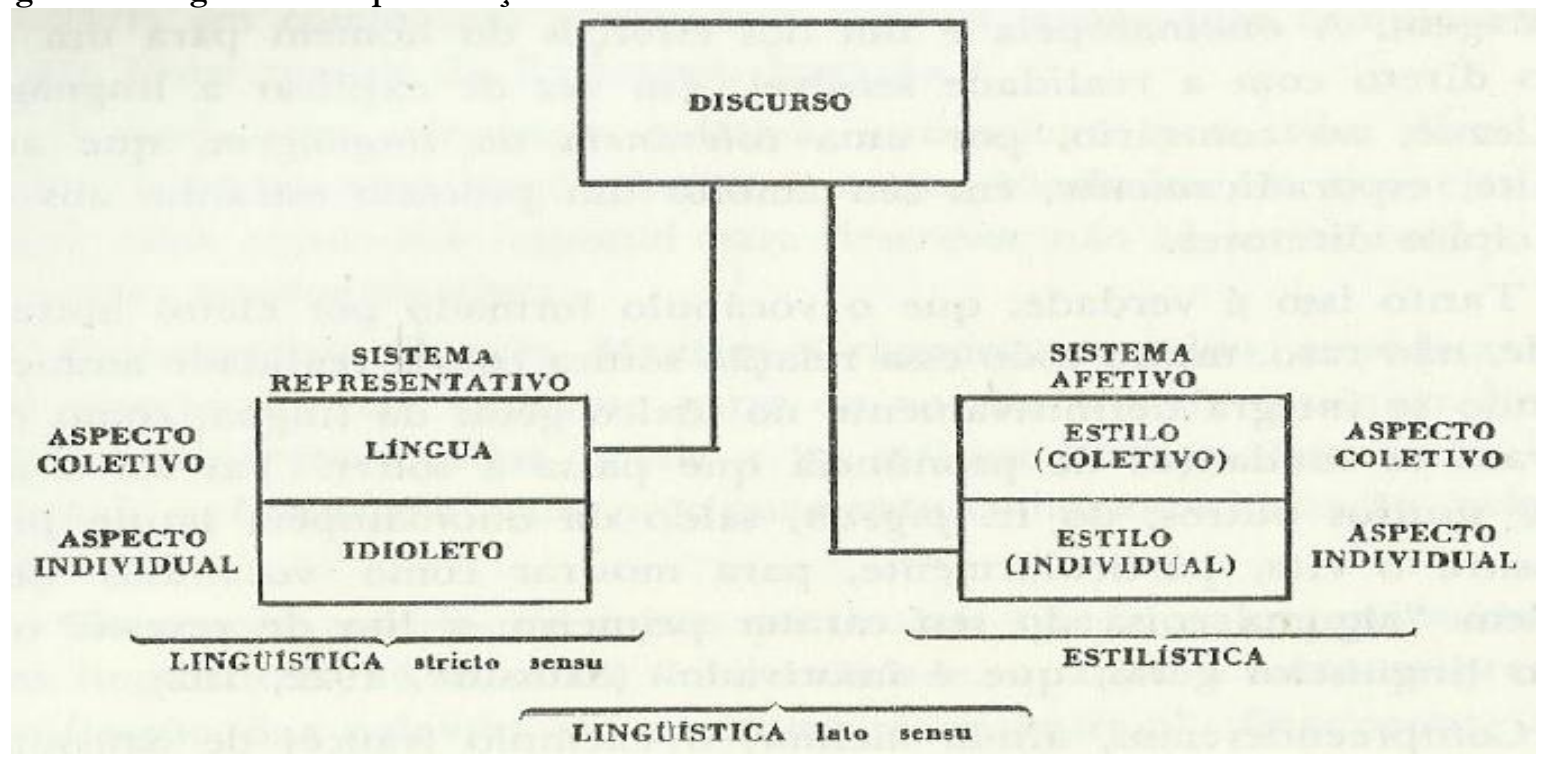

Fonte: Camara Jr. (1989, p.29).

A variação intergrupal nesse sentido adquire significado de diferenciação dos usos de uma mesma língua em contextos geograficamente distantes. Ninguém fala igual ao outro. É por essa razão que em linguística forense se compara a fala/escrita a uma impressão digital, pois o estilo individual representado na fig.1 apresenta as particularidades individuais dos membros de uma comunidade linguística. Quando ocorre contato entre grupos portugueses, angolanos, moçambicanos e brasileiros se efetiva a percepção das diferenças linguísticas entre os grupos em contato porque os discursos marcam essa diferença variacional que por sua vez se desdobra em variantes. Se o contato for dentro de uma mesma comunidade linguística, onde os subgrupos pertencem a um determinado grupo e de algum modo entram em contato. Já que a variação intergrupal é o resultado da interação que se realiza pela diferença entre grupos que compõem uma mesma comunidade linguística. Como exemplos da interação intergrupal do PB podemos citar os falares das diferentes regiões, as diferenças lexicais e fonético-fonológicas dentro do 
grupo maior: a variedade brasileira. Com isso a variação intergrupal se efetiva através das variantes no contexto do $\mathrm{PB}$. O que significa dizer que as variantes são formas individuais específicas de subgrupos diferentes, de uso de uma mesma variedade linguística, por exemplo: o falar gaúcho, o falar goiano, o falar amazonense etc.

As variações intragrupais são essenciais na constituição da variedade de um mesmo sistema linguístico, uma vez que cada canto do espaço de uso da língua tende a usá-la de acordo com as necessidades dos membros dos subgrupos. Tal variação se dá nos mesmos planos da variação intergrupal. A única diferença é que esta se vincula ao intercâmbio num mesmo contexto linguístico, ou melhor, dentro de uma mesma comunidade linguística. Para tanto, essa variação se reflete nas diferenças linguísticas existentes dentro de um mesmo grupo, nesse caso o falar baiano se enquadra dentro do grupo PB, que está integrado dentro do sistema LP.

Essas variações são fundamentais ao estudo de línguas em sua realização concreta, visto que todas as línguas dispõem de fenômenos deste grau. O PB é um exemplo riquíssimo que prova a existência de fenômenos linguísticos que modelam e especificam a variedade brasileira perante as outras variedades da LP. Contudo, a língua é do povo e só existe para o povo, sendo assim é indispensável a sua ligação com a cultura atuante no meio onde vive esse povo.

\section{CONSIDERAÇÕES FINAIS}

A relevância da memória social para melhor entender as questões linguísticas do português falado no Brasil e a suas peculiaridades em relação aos demais usos da LP mundo a fora, se constitui como fator fundamental no desenvolvimento de estudos que priorizem a língua em contexto social como objeto de pesquisa. É nela que se encontra elementos precisos que modificaram a LP ao ser transplantada além-mar, tornando-a diferente em cada espaço lusófono onde atua. A dimensão social presente na cultura a qual está sujeito o indivíduo é fator condicionante para a construção da sua identidade e já agora um dos meios visíveis para se perceber essa influência é o recurso ao uso da memória. Esta funciona como repositório de todo passado histórico social e cultural que sustenta as bases de formação histórica de um povo em uma determinada comunidade, seja em nível linguístico ou cultural.

A formação da identidade do ator social se desenvolve de acordo com o meio e a relação que cada pessoa mantém com o meio ao qual está inserido, visto que para viver em comunidade o sujeito deve comungar aspectos culturais e linguísticos que fazem parte da memória social da comunidade onde vive. Neste contexto se sobrepõe todo o passado histórico linguístico-cultural que de algum modo sobrevive no contexto atual de cada comunidade de fala portuguesa. É a partir disso que estudar a LP e perceber suas variações se torna interessante, já que o próprio território brasileiro proporcionou o suporte necessário para tal diferenciação. Sendo assim, o PB é uma contextualização da LP à realidade sócio histórica e linguístico-cultural brasileira. A sua conformação ao espaço brasileiro diz muito sobre a diversidade cultural e linguística encontrada no país em épocas passadas. Desse modo é justificável a existência de variedades de uma mesma língua que por fim se configura em mudanças internas da qual fazem parte as variantes linguísticas.

O multiculturalismo que faz parte da formação, desenvolvimento ou conformação de uma língua ao meio onde atua é pertinentemente adequado para a efetivação do processo de diferenciação entre as línguas e até mesmo dentro de uma única língua. $\mathrm{O}$ fato de existir várias culturas onde atua determinada língua não a torna melhor ou pior àquela que existe em contextos de uma só cultura, pois as línguas são flexíveis e se adaptam aos moldes do contexto onde atua. É importante sublinhar esta questão, porque não existem línguas melhores que outras, não existem variedades melhores que outras, pois, cada língua ou variedade se adapta à realidade sociocultural em que os seus falantes estão inseridos. 
Portanto, a LP encontrou no Brasil um espaço recheado de culturas e línguas indígenas que muito contribuíram para a consolidação da variedade. Isso quer dizer que o encontro diversificado deu margem para o desenvolvimento de uma nova face do português em relação ao português europeu. Mas, essa face nova que no Brasil se confirmou não é uma contradição ao português europeu, mas sim uma adaptação, uma adequação ao contexto do povo que a abrigou. A variedade não pode ser considerada como língua, pois ela apresenta traços fortíssimos da língua. Atribuir o nome de "brasileiro" (BAGNO, 2004), "língua brasileira" ou "brasilês" seria um equívoco de análise, pois as características linguísticas do PB mostram ainda traços sólidos que a ligam diretamente à LP. Chamamos atenção ao fato de que não dissemos português europeu, porque o português europeu também é uma variedade da LP. Jamais afirmamos que o português europeu é a variedade melhor que as outras. Isso seria preconceito e falta de conhecimentos de pesquisas atuais sobre as variedades da LP. É provável (acreditando que as línguas mudam e variam) que nos próximos séculos ou décadas se possa afirmar com dados reais resultantes de pesquisas científicas que, o que se fala/escreve no Brasil já não é mais LP, mas sim "brasilês" ou "brasileiro" ou "língua brasileira".

Suponhamos que iniciemos (sem apresentar estudos científicos) a atribuição de nomes para as variedades do português na lusofonia. Assim teríamos moçambicanês, angolanês, são tomês e príncipe, timor leste e por aí em diante. Olhemos para as outras línguas mais faladas tais como o inglês, o espanhol, o francês, o swahili, mandarim, etc., que apesar da existência de variedades jamais se ousou a atribuir nomes particulares as mesmas. Tal fato não aconteceu não por falta de vontade de apagar o nome do colonizador, mas por falta de características suficientes que avançam para uma afirmação mais sólida do distanciamento que permite afirmar que esta ou aquela já é uma língua isolada. Concordamos com a ideia de que o PB tem uma identidade própria, uma "identidade nacional, construída a duras penas" (BAGNO, 2004), mas em nenhum momento esta variedade deixou de ser fiel aos recursos disponíveis ao sistema da LP. É bom lembrar que o sistema linguístico é um sistema de possibilidades que permite as combinações possíveis escolhidas por cada usuário e que correspondem às suas necessidades comunicativas.

Nesse sentido, o PB tem o direito de se adaptar às realidades socioculturais dos seus falantes, mas em nenhum momento infringe as "imposições" do sistema. Cremos que a partir do momento em que o PB desobedecer as "imposições" do sistema da LP estará criando uma afirmação própria, uma característica que o permitiria afirmar que deixou de pertencer a LP. Muitos pesquisadores ainda relacionam a LP como língua do colonizador, mas isso não constitui verdade, pois na lusofonia ninguém fala um português melhor do que o outro. Aliás, a muito tempo os países lusófonos alcançaram a independência e não dependem mais de Portugal politicamente.

A LP usada (falada/escrita) pelas comunidades lusófonas pertence à todos que se valem dela para se comunicarem e não mais é patrimônio linguístico e cultural único e exclusivo de Portugal, quer dizer, Portugal ficou na memória histórica. Esta verdade histórica ninguém pode apagar, nem com a mudança de "português" para "brasilês ou brasileiro". É natural que em algum momento recorramos ao latim para compreender a origem de certas palavras, mas isso é apenas lembrança (memória linguística e histórica). A nossa vida é feita de memórias, memórias essas que moldam o futuro. Isso acontece na língua sem reconhecermos a língua como sendo propriedade da comunidade e dos falantes que a usa e são estes que em última instância definirão o seu destino. Essas análises nos levam a concluir que existe uma única língua portuguesa no espaço lusófono cuja esta varia segundo os contextos específicos. Portanto, podemos falar de português de Moçambique, português angolano, guineense e por aí em diante.

As línguas naturais (swahili, português, mandarim, juruna, wauja, kabuverdiano) possuem uma memória cultural, social e histórica muito ampla e abrangente do que as línguas artificiais (esperanto, rugresk, interlíngua, PLN, kingon, na'vi, sildavo, etc.). Destacou-se ampla e abrangente para justificar que nas línguas naturais a origem se confunde com o surgimento do ser 
humano. Reconhecer a origem do humano é ao mesmo tempo reconhecer o início da língua, pois o ser humano sempre precisou se comunicar.

Os objetivos traçados para o desenvolvimento deste artigo foram de modo geral satisfeitos, vez que a discussão que se seguiu analisou a memória social como repositório do pluralismo linguístico-cultural no contexto específico brasileiro. O ator social se constitui como parte da comunidade a que pertence mediante as coordenadas culturais e linguísticas que a engendra. No caso do Brasil, o brasileiro carrega em sua identidade linguística uma dimensão cultural diversificada e complexa, vez que a presença de elementos culturais indígenas, africanas, portuguesas etc. são marcas fundamentais para se entender o ser brasileiro hoje. A relação que se estabelece entre LP e cultura brasileira denuncia o quão forte foram as influências externas e internas no processo de adaptação do português no Brasil.

\section{REFERÊNCIAS BIBLIOGRÁFICAS}

AUROUX, Sylvia. Filosofia da linguagem. Trad. Marcos Marcionilo. São Paulo: Parábola, 2009.

BAGNO, Marcos. Português ou brasileiro: um convite à pesquisa. São Paulo: Parábola, 2004.

BAGNO, Marcos. O que é uma língua? imaginário, ciência e hipóstase. In: LAGARES, X. C.; BAGNO, Marcos. (Org.). Políticas da norma e conflitos linguísticos. São Paulo: Parábola, editorial, 2011. p.355-388.

BAGNO, Marcos. Lingua, linguagem, linguística: pondo os pingos no ii. 1. ed. São Paulo: Parábola, 2014.

BECHARA, Evanildo. Moderna gramática portuguesa. 37. ed. Rio de Janeiro: Nova Fronteira/ Lucerna, 2009.

BOSI, Alfredo. Dialética da colonização. São Paulo: Companhia das Letras, 1992.

CAMARA JR, Joaquim M. Principios da linguística geral. Rio de Janeiro: Padrão, 1989.

CASTILHO, Ataliba Teixeira. de. Nova gramática do português brasileiro. São Paulo: Contexto, 2010.

COELHO, Izete Lehmkul. et al. Para conhecer sociolinguística. São Paulo: Contexto, 2015.

COSERIU, Eugene. Teoria da linguagem e lingüistica geral. Rio de Janeiro/ São Paulo, Presença/ EDUSP, 1979.

DIETRICH, W. Conservação e inovação no campo léxico do parentesco: o caso do Mbyá e do Guaraní paraguaio (Tupí-Guaranî). Revista Brasileira de Linguística Antropológica. Brasília, v.6, n. 1, p.195-216, jul.2014.

GORSKI, Edair Maria; COELHO, Izete Lehmkuhl.; SOUZA, Christiane Maria N. de. (Org.). Variação estilística: reflexões teórico-metodológicas e propostas de análise. v.3. col. Florianópolis, Insular, 2014.

HALBWACHS, Maurice. A memória coletiva. Trad. Beatriz Sidou. São Paulo: Centauro, 2006.

HALL, Stuart. Pensando a diáspora: reflexões sobre a terra no exterior. In: (Org.). $D a$

diáspora: identidades e mediações culturais. Trad. Adelaine La Guardia Resende et al. 1. ed. Belo Horizonte: Ed. UFMG, 2003. p.25-50.

INSTITUTO NACIONAL DE ESTATÍSTICA DE MOÇAMBIQUE: Recenseamento geral da população e habitação. Maputo: INE, 2009.

LABOV, William Padrões sociolinguísticos. Trad. Marcos Bagno, Maria Marta P. Scherre e Caroline R. Cardoso. São Paulo: Parábola editorial, 2008.

LOPES, Edward. Fundamentos da linguistica contemporânea. 2. ed. São Paulo: Cultrix, 1980.

MARTINET, André. Éléments de linguistique générale. Paris: Armand Colin, 1967.

MATEUS, Maria Helena Mira. Se a lingua é um factor de identificaşão cultural, como se compreenda que uma lingua viva em diferentes culturas? Rio de Janeiro: FLUL, 2001.

PAULA, Maria Helena. de. Rastros de velhos falares: léxico e cultura no vernáculo catalano. Tese (Doutorado em Linguística e Língua Portuguesa), Faculdade de Ciências e Letras, Universidade Estadual Paulista, Araraquara, 2007. 
SAPIR, Edward. A linguagem: introdução ao estudo da fala. Trad. Joaquim Mattoso Câmara. Rio de Janeiro: Instituto Nacional do Livro, 1954.

SAUSSURE, Ferdinand de. Curso de linguística geral. Trad. Antônio Chelini, José Paulo Paes, Izidoro Blikstein. 27.ed. São Paulo: Cultrix, 2006.

SOARES, Magda. Concepção de linguagem e o ensino de língua portuguesa. In: BASTOS, N.B. (Org.) Lingua portuguesa: história, perspectiva e ensino. São Paulo: EDUC / IP-PUC/SP, 1998.

TEYSSIER, Paul. História da língua portuguesa. Trad. Celso Cunha. São Paulo: Martins Editora, 2014.

TIMBANE, Alexandre António. Análise sociodiscursiva da "saudação" do grupo étnicolinguístico tsonga de Moçambique. Revista educação, cultura e sociedade. v.4, n.2, p.90-105, jul./dez.2014a.

TIMBANE, Alexandre António. A lexicultura do português de Moçambique. Linguagem: estudos e pesquisas. Catalão, v.18, n.2, p.43-59, jul,/dez.2014b.

TIMBANE, Alexandre António; REZENDE, Meire Cristina Mendonça. A língua como instrumento opressor e libertador no contexto lusófono: o caso do Brasil e de Moçambique. Travessias. Cascavel, v.10, n.3, 28.ed. p.388-408, 2016.

VANNUCCHI, Aldo. Cultura brasileira: o que é, como se faz. 5.ed. São Paulo: Loyola, 2011.

Recebido em 23/05/2017

Aceito em 31/07/2017

Publicado em 21/08/2017 